\title{
PERCEPTION ON DENGUE AND ITS PREVENTION AMONG CONSTRUCTION WORKERS IN MKCG MEDICAL COLLEGE CAMPUS, BERHAMPUR, ODISHA- A CROSS-SECTIONAL STUDY
}

\author{
Parsuram Jena ${ }^{1}$, Dhaneswari Jena ${ }^{2}$, Uttar Kumar Dandapat 3 , Srabani Pradhan', Dillip Kumar Mahapatra ${ }^{5}$, Pravati Jena ${ }^{6}$ \\ ${ }^{1}$ Assistant Professor, Department of Medicine, SCB Medical College, Cuttack. \\ ${ }^{2}$ Associate Professor, Department of Community Medicine, MKCG Medical College, Berhampur. \\ ${ }^{3}$ Postgraduate Student, Department of Community Medicine, MKCG Medical College, Berhampur. \\ ${ }^{4}$ Postgraduate Student, Department of Community Medicine, MKCG Medical College, Berhampur. \\ ${ }^{5}$ Assistant Professor, Dr. Ambedkar Global Law Institute, Tirupati, Andhra Pradesh. \\ ${ }^{6}$ Tutor, School of Nursing, MKCG Medical College, Berhampur.
}

\begin{tabular}{l}
\hline ABSTRACT \\
BACKGROUND \\
Dengue is a major public health concern due to rapid urban and rural infrastructure development. So a study was conducted on \\
Objectives- To assess the knowledge of the study population on different aspects of dengue and its preventive methods.
\end{tabular}

\section{MATERIALS AND METHODS}

Type of study- Cross- sectional study.

Place of study- MKCG Medical College Campus, Berhampur.

Duration of study- 1 month, June 2017.

Study population- 216 construction workers of L \& T Company.

Sampling method- Convenient sampling. After obtaining IEC approval and verbal consent from authority (L \& T) and the study population, data were collected using scientifically designed pre-tested questionnaire.

Statistical analysis - Percentage.

\section{RESULTS}

85.2\% study population were from rural areas and 57.4\% from outside state. They are construction workers (53.7\%), supply workers (27.8\%), officials (13\%) and scavengers (5.6\%). 100\% had heard of dengue. Of them $48.8 \%$ heard it from mass media. $100 \%$ knew mosquito bite causes dengue. $41 \%$ opined that mosquito causing dengue bites in day time. $43.6 \%$ participants knew the symptoms as fever and rigor. $41 \%$ told that use of mosquito net can give protection against mosquito bite. Filling of the ditches $(70 \%)$ \& proper disposal of garbage $(22 \%)$ and of unused container $(8 \%)$ was mentioned to be the preventive measure for mosquito breeding.

\section{CONCLUSION}

Workers had insufficient knowledge about the disease, its causes or its prevention. Though they are at more risk of developing disease, they lack the preventive knowledge. It is recommended that the authority should promote drive for health awareness campaign and screening among workers by health personnel as well as elimination of breeding ground of mosquito.

\section{KEYWORDS}

Dengue, Perception, Construction Workers.

HOW TO CITE THIS ARTICLE: Jena P, Jena D, Dandapat UK, et al. Perception on dengue and its prevention among construction workers in MKCG medical college campus, Berhampur, Odisha- A cross-sectional study. J. Evolution Med. Dent. Sci. 2017;6(93): 6726-6729, DOI: $10.14260 /$ jemds/2017/1456

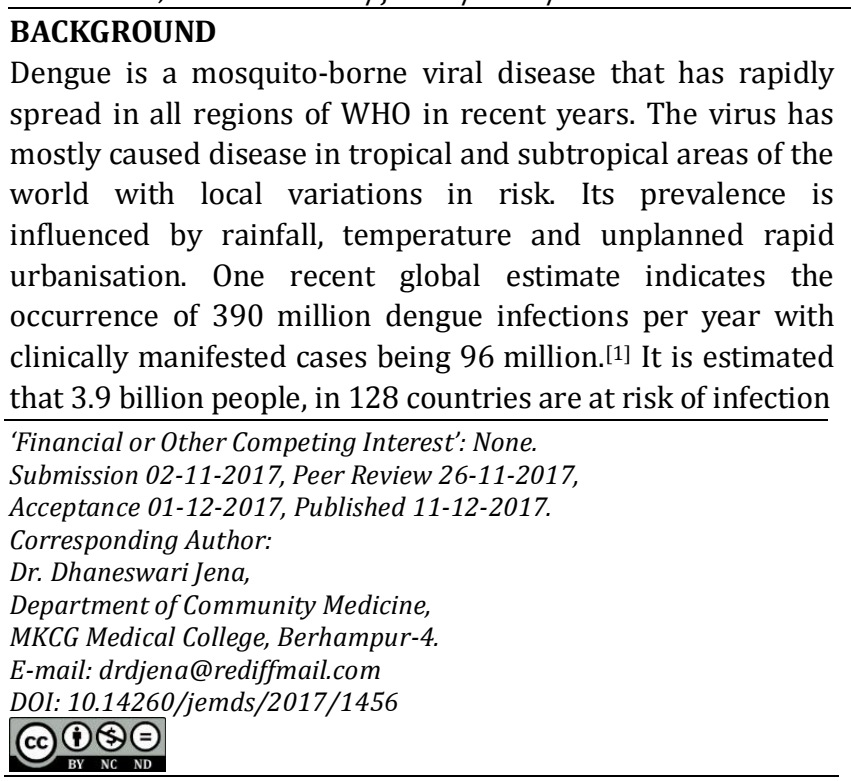
with dengue viruses.[2] Member States in three WHO regions reported dengue cases increased from 2.2 million in 2010 to 3.2 million in 2015.[3] Its epidemiological patterns, multiple dengue virus serotypes in many countries and the alarming impact on both human health and the global and national economies confer it world importance. In India 36635 dengue cases were reported under National Vector Borne Disease Control Programme (NVBDCP) so far in 2017. Of all the state and union territories, the maximum number of dengue cases have been reported in Kerala (16530), followed by Tamil Nadu (6919) till 20 th August. Considering the annual status of Dengue Burden in India, 129166 cases and 245 deaths occurred in the year 2016. In Odisha, the number of cases was 8380 with 11 deaths reported in 2016 and 455 cases with 2 deaths occurred till 20th August 2017.[4]

Dengue can cause broad range of clinical manifestations including asymptomatic infection, mild flu-like symptoms, and the more severe haemorrhagic fever. This syndrome is associated with $40-50 \%$ fatality if untreated or mistreated. 
When properly treated, the case fatality can be reduced to $5 \%$ or less.[5] Even though there is no specific treatment for dengue/severe dengue, early detection and access to proper medical care can lower case fatality rates below $1 \%$.(3) Due to lack of vaccine or specific treatment, control and preventive measures need greater emphasis. Wide spread community awareness on control and prevention can halt its spread. Occurrence and spread of dengue involves urban \& rural infrastructure development activities. Construction workers are at more risk of infection due to lack of sanitation and hygiene in their temporary settlements. Their perception about the disease causation and prevention influences vulnerability status of the workers and spreading potential of disease from one region along with migration of these workers. With this background, effort has been put to carry out a study with following objectives.

\section{Objectives}

To assess the knowledge on different aspects of dengue among the study population and to assess their knowledge on preventive methods.

\section{MATERIALS AND METHODS}

Study Design

A Cross- Sectional study.

\section{Study Area}

The study was carried out among workers of L\&T Company working in MKCG Medical College Campus, Berhampur.

\section{Study Period}

One month period (June 2017) adopting convenient sampling. Prior to that, IEC approval and verbal consent from authority (L\&T) and study population were obtained.

\section{Data Collection}

Data was collected from participants with personal interview, using a scientifically designed semi-structured pretested questionnaire.

\section{Study Participant}

216 cases were taken as study participants. They were workers of L\&T Company, working for construction of buildings of medical college.

\section{Analysis}

Data was analysed in the Department of Community Medicine, MKCG Medical College.

\section{RESULTS}

\begin{tabular}{|c|c|c|c|}
\hline Profile & Category & Number & Percentage \\
\hline \multirow{3}{*}{ Age } & $18-25$ & 64 & 29.6 \\
\cline { 2 - 4 } & $26-40$ & 92 & 42.5 \\
\cline { 2 - 4 } & $>40$ & 60 & 27.7 \\
\hline \multirow{2}{*}{ Religion } & Hindu & 142 & 65.7 \\
\cline { 2 - 4 } & Muslim & 74 & 34.2 \\
\hline \multirow{3}{*}{ SES } & BPL & 128 & 59.2 \\
\cline { 2 - 4 } & APL & 88 & 40.8 \\
\cline { 2 - 4 } & Others & 184 & 85.2 \\
\hline \multirow{2}{*}{ Residence } & Rural & 32 & 14.8 \\
\cline { 2 - 4 } & Urban & 92 & 42.5 \\
\hline State & Odisha & & \\
\hline
\end{tabular}

\begin{tabular}{|c|c|c|c|}
\hline & $\begin{array}{c}\text { Others (West Bengal, } \\
\text { Jharkhand, } \\
\text { Chhattisgarh) }\end{array}$ & 124 & 57.5 \\
\hline \multirow{4}{*}{ Type of work } & Construction worker & 116 & 53.7 \\
\hline & Supply worker & 60 & 27.9 \\
\hline & Official & 28 & 12.9 \\
\hline & Waste disposal & 12 & 5.5 \\
\hline
\end{tabular}

\begin{tabular}{|c|c|c|}
\hline Disease Transmission & Number & Percentage \\
\hline Mosquito bite & 216 & 100 \\
\hline Mosquito bite at day time & 104 & 48.1 \\
\hline Drinking dirty water & 32 & 14.8 \\
\hline Unhygienic food & 41 & 19 \\
\hline Houseflies & 12 & 5.5 \\
\hline \multicolumn{3}{|c|}{ Signs and Symptoms } \\
\hline Fever & 216 & 100 \\
\hline Nausea/Vomiting & 102 & 47 \\
\hline Bleeding & 19 & 8.7 \\
\hline Muscular pain & 86 & 39.8 \\
\hline Headache & 88 & 40.7 \\
\hline Rash & 15 & 6.9 \\
\hline \multicolumn{3}{|l|}{ Treatment } \\
\hline Hospital & 194 & 89.8 \\
\hline Home & 3 & 1.4 \\
\hline Traditional practice & 19 & 8.7 \\
\hline \multicolumn{3}{|c|}{ Preventive Methods } \\
\hline Mosquito Mat/Coil/Liquid Vapouriser & 190 & 87.9 \\
\hline Mosquito Spray & 186 & 86.1 \\
\hline Mosquito Net & 43 & 19.9 \\
\hline Window \& Door Screen & 23 & 10.6 \\
\hline Cleaning House & 84 & 38. \\
\hline Cleaning of garbage/trash & 67 & 31 \\
\hline $\begin{array}{c}\text { Use of Smoke to drive away } \\
\text { mosquitoes }\end{array}$ & 31 & 14.3 \\
\hline
\end{tabular}

\begin{tabular}{|c|c|c|}
\hline Sources & Number & $\mathbf{\%}$ \\
\hline Radio & 122 & 56 \\
\hline Television & 68 & 31.4 \\
\hline Friends \& Neighbours & 46 & 21.2 \\
\hline Newspapers/Magazines & 29 & 13.4 \\
\hline Health personnel & 13 & 6 \\
\hline Schools & 10 & 4.6 \\
\hline Brochures & 2 & 0.9 \\
\hline Banners & 1 & 0.4 \\
\hline Table 3. Source of their Knowledge \\
\hline
\end{tabular}

\section{DISCUSSION}

Out of total 216 study cases, majority (42\%) were between age 26 to 40 years of age, mean age being 35 . Majority $(65.7 \%)$ were Hindu by religion, mostly $(85 \%)$ from rural areas and $57 \%$ were from states other than Odisha. About $60 \%$ were from poor families who possess BPL card. By nature of work, 54\% were construction workers followed by supply workers, others were officials and scavengers by profession.

All the workers had knowledge on dengue which was similar to study of Tyagi et al[6] and it was better than the studies of Bota R et al (94.6\%),[7] Acharya et al (90\%),[8] Irat A et al (89.9\%),[9] S Jeelani et al (86\%),[10] Degallier $\mathrm{N}$ et al (78\%),[11] and Swaddiwudhipong W et al (67\%).[12] Chinakalli et al showed in their study that majority of participants heard about dengue.[13] The cause of dengue as mosquito bite was known to all the participants in the present study. Similar 
observation was made by Tyagi et al (100\%) and M Ho et al (95.8\%) where the participants knew that mosquito bite transmits this disease.[6],[14] It was also seen that majority $(90.5 \%)$ of the respondents had a fair knowledge about the vector in study of Qureshi E et al.[15] 'Mosquito bite' is the most common cause of dengue mentioned by $68 \%$ and $60.6 \%$ of participants in the study of Khamis et al and Naik et al respectively.[16],[17] In the present study, prevalence of other faulty ideas like transmission of the disease by unhygienic food, drink and housefly were observed. However, in study of Anima $\mathrm{H}$ et al, $88 \%$ participants were unaware regarding the causative agent of disease.[18] $91.5 \%$ participants in study of Rehman A et al knew that dengue fever is caused by Aedes mosquito.[19] 58.6\% of participants reported "Aedes mosquito" as a vector as per study of Bota R et al.[7] Forty eight percent participants in the present study knew about biting time i.e. day time, similar to Bota et al where $52.2 \%$ participants could tell the time ${ }^{[7]}$ and much less $(24 \%)$ observed by Chinakali et al.[13]

Assessing the awareness on symptoms of dengue, fever as the symptoms was known to all of them. But in study of Jeelani S et al, 59\% could tell fever is the commonest symptom.[10] Prolonged high fever was mentioned as the symptoms by most of the participants as observed by Bota $\mathrm{R}$ et al[7] and other studies conducted in Brazil,[11] Hong Kong,[14] Pakistan,[15] Northern Thailand, Cambodia. In the study of Queresi $\mathrm{N}$ et al, high grade fever was mentioned by $41.4 \%$ as the most common and obvious symptoms.[15] Even in the study of Haldar A et al, $27.9 \%$ of the respondents were not aware about other signs and symptoms of the disease except fever (68.9\%).[18] Dengue specific symptoms of bleeding and rash, were mentioned by only $2 \%$ and $11 \%$ of the study participants, respectively in the study of Chinakali $P$ et al.[13] Bleeding from any site as a symptom was mentioned by few of them. Insufficient knowledge on symptoms, was found in the present study, as vomiting (47\%), muscular pain $(40 \%)$ and headache $(40 \%)$ were also mentioned by few of them. It is similar to study of Bota $\mathrm{R}$ et al where muscular pain $(39.6 \%)$, bleeding and headache $(41.35 \%)$, nausea and vomiting (44.75\%) were mentioned by the participants. [7] In other studies, awareness about fever, body ache and shivering were mentioned as dengue symptoms, by $93.5 \%$, $85.3 \%$ and $83 \%$ respectively and least mentioned symptom was nausea and vomiting (74.2\%).[19] In the study of Taksande \& Lakhkar (2012) et al, only $8.04 \%$ and $0.97 \%$ of participants told the muscular pain and nausea/vomiting as the symptoms of dengue.[20] Bleeding and rashes were other common symptoms mentioned in the study of Itrat A et al.[9] Benthem et al reflected in their study, rash or bleeding is a specific symptom of dengue infection and not common in other febrile illnesses indicating that the majority of people can distinguish dengue infection from other diseases.[21] Naik et al reported in their study that $34.9 \%$ of the respondents were not aware of symptoms of DF.[17]

In the present study, mosquito coil/mats are preferred by most of the participants (82\%) to prevent mosquito bite and dengue prevention. In the study of Khun $\mathrm{S}$ et al, mosquito spray (86\%) and mosquito mat/coil/liquid vapourisers (88\%) were mentioned as preventive method. In other studies, majority $(70.3 \%)$ knew about mosquito repellents like mat/liquid vapouriser/coils.[22] Community respondents $(40.7 \%)$ were relying on the insecticidal sprays to prevent mosquito bites as observed by Quresi $\mathrm{N}$ et al.[15] Fradin MS et al and Jelinek $\mathrm{T}$ et al found in their study that preventive measures preferred were use of mosquito sprays and coils.[23],[24] Keeping environment clean (71\%), application of insecticidal cream (48\%), use of smoke (34\%), liquidator (30\%), covering body with clothing (26\%) and mosquito net (23\%) are different other methods mentioned in present study. Also filling of the ditches (70\%) \& proper garbage disposal $(22 \%)$ \& proper disposal of unused container $(8 \%)$ were mentioned to be the preventive measures of mosquito breeding mentioned by the participants, More than half (55.7\%) mentioned "Cleaning of the house" as an important preventive practice, and other preventive measures cited were prevention of water stagnation (46.5\%), insecticidal spray $(42.8 \%)$, use of oil in cooler $(31.9 \%)$ and mosquito net (26.6\%) in Naik's study.[17] Nelliyanil et al[25] observed mosquito net $(45 \%)$ was the most common method used for mosquito bite prevention followed by coil. In Brazil, elimination of water containers was the most efficient means of control of DF according to 73\% of people.[11] A survey of KAP of the prevention of DHF in an urban community of Thailand reported that covering water containers was the most common practice to prevent mosquito breeding in drinking-water containers.[13] However, this type of knowledge is minimal in present study which needs improvement. Naik et al observed that only $51.36 \%$ were aware of preventive measures for DF.[17] 30.4\% were aware regarding one or more means of preventive measures.[18]

In the present study, radio was the major (56\%) source of information. Television (31.4\%), friends and neighbours (21\%) and newspapers/magazines (13\%) are other important sources of information about dengue for them. It is similar to the studies from South Delhi, East Delhi and Kuala Lumpur,[6] [25] [26] but contrast to the study of Chinakali et al, where television was the most important source of information (54.9\%).[13] Qureshi et al observed 60.7\% reported $\mathrm{TV} /$ radio both as the major source of knowledge about dengue.[15] In study of Acharya et al,[8] important sources of information about dengue were television (59\%), health personnel (38\%), friends and neighbours (30.5\%) and schools $(8.32 \%)$. Unfortunately, health personnel constitute $6 \%$ of the source in present study. It is also much less than the study of Sayabhang et al study where health personnel as a source were $31.88 \%$ Role of media like magazines (22\%) and newspapers $(16.47 \%)$ was more among them except the radio $(5 \%)$ which is very low in comparison to present study. ${ }^{[26]}$ Also newspaper was the important source (85\%) of information in case of study of Khamis et al.[16] In study of Sayavong et al, local television (88.89\%) and radio (65.70\%) were mentioned by the participants.[26] In Haldar A et al study about the sources of information regarding signs and symptoms of the disease, majority got the information from the mass media (65\%), on mode of transmission and prevention of disease, sources (19\%) like relatives, neighbours, elder members of the family, etc., about the aetiology, vectors and facts of the disease; $9 \%$ got the information from the health personnel; $7 \%$ of the respondents did not get any information from any sources. [18]

\section{CONCLUSION}

Low prevalence of knowledge on dengue was observed in the present study population. Perception on dengue, mode of 
transmission was adequate though some faulty thinking regarding transmission was observed. Knowledge regarding time of bite, signs and symptoms other than fever and preventive measures was much far from satisfactory. Preventive measures mentioned by them mostly focused towards protection from mosquito bites during night time. Awareness about avoiding day time bite by wearing full, light coloured, loose clothing during day was less. Source of knowledge is deficient and not oriented towards prevention of mosquito bite during day time. Inadequate knowledge is a deterrent to preventive practice of dengue.

\section{Recommendation}

Elimination of mosquito breeding place in the house and at workplaces should be promoted. Observation of national dengue day on May $16^{\text {th }}$ should be sincerely observed. Area and risk specific plans should be developed and implemented. Behavioural change communication should be utilised to transform the knowledge into practice.

\section{Limitation}

The questionnaire, though pretested, was not validated. The above observations may be true only for the study population because of convenience sample and cannot be generalised.

\section{ACKNOWLEDGEMENT}

We are thankful to all the participants who joined the study voluntarily and the L\&T authority for allowing their workers to participate.

\section{REFERENCES}

[1] Bhatt S, Gething PW, Brady OJ, et al. The global distribution and burden of dengue. Nature 2013;496(7446):504-7.

[2] Brady OJ, Gething PW, Bhatt S, et al. Refining the global spatial limits of dengue virus transmission by evidence-based consensus. PLoS Negl Trop Dis 2012;6(8):e1760.

[3] www.who.int.mediacentre/factsheets/s117/en.

[4] nvbdcp.gov.in/den-cd.html.

[5] Heyman DL. American Public Health Association APHA. Communicable Diseases Manual. 19th edn. Washington DC 2008.

[6] Tyagi P, Roy A, Malhotra MS. Knowledge, awareness and practices towards malaria in communities of rural, semi-rural and bordering areas of east Delhi (India). J Vect Borne Dis 2005;42(1):30-5.

[7] Bota R, Ahmed M, Jamali MS, et al. Knowledge, attitude and perception regarding dengue fever among university students of interior Sindh. J Infect Public Health 2014;7(3):218-23.

[8] Acharya A, Goswami K, Srinath S, et al. Awareness about dengue syndrome and related preventive practices amongst residents of an urban resettlement colony of south Delhi. J Vect Borne Dis 2005;42:122-7.

[9] Itrat A, Khan A, Javaid S, et al. Knowledge, awareness and practices regarding dengue fever among the adult population of dengue hit cosmopolitan. PLoS One 2008;3(7):e2620.

[10] Jeelani S, Sabesan S, Subramanian S. Community knowledge, awareness and preventive practices regarding dengue fever in Puducherry - south India Public Health 2015;129(6):790-6.
[11] Degallier N, Vilarinhos PT, de Carvalho MS, et al. People's knowledge and practice about dengue, its vectors, and control means in Brasilia (DF), Brazil: Its relevance with entomological factors. J Am Mosq Contr Assoc 2000;16(2):114-23.

[12] Swaddiwudhipong W, Lerdlukanavonge P, Khumklam $\mathrm{P}$, et al. A survey of knowledge, attitude and practice of the prevention of dengue hemorrhagic fever in an urban community of Thailand. Southeast Asian J Trop Med Public Health 1992;23(2):207-11.

[13] Chinnakali P, Gurnani N, Upadhyay RP, et al. High level of awareness but poor practices regarding dengue fever control A cross-sectional study from North India. North Am J Med Sci 2012;4(6):278-82.

[14] Ho M, Luk Y, Choy RYL. Knowledge, attitude and practices of Hong Kong residents for dengue fever prevention. The Hong Kong Practitioner 2006;28:6875.

[15] Qureshi EMA, Vehra S, Ghafoor GZ, et al. Community perception regarding dengue epidemic in Lahore, Pakistan. Pakistan Journal of Science 2014;66(1):7-10.

[16] Ibrahim NK, Al-Bar A, Kordey M, et al. Knowledge, attitudes, and practices relating to Dengue fever among females in Jeddah high Schools, J Infect Public Health 2009;2(1):30-40.

[17] Naik PR, Nirgude AS, Praksh GK. Knowledge and preventive practices regarding dengue among adult population of rural area of Nalgonda district, South India. Int J Biol Med Res 2011;2(3):652-5.

[18] Haldar A, Gupta UD, Majumdar KK, et al. Community perception of dengue in slum areas of metropolitan city of West Bengal. J Commun Dis 2008;40(3):205-10.

[19] Rahman AA, Zainuddin H, Minhat HS, et al. Community perception towards dengue and dengue prevention program among residences of a rural settlement in Jempol, Negeri Sembilan. International Journal of Public Health and Clinical Sciences 2014;1(1):13-23.

[20] Taksande A, Lakhkar B. Knowledge, Attitude and Practice in the Rural Area of Central India. Shiraz EMedical Journal 2012;13(4):146-57.

[21] Van Benthem BH, Khantikul N, Panart K, et al. Knowledge and use of prevention measures related to dengue in northern Thailand. Tropical Medicine \& International Health 2002;7(11):993-1000.

[22] Khun S, Manderson L. Community and school-based health education for dengue control in rural Cambodia: a process evaluation. PLoS Neglected Tropical Diseases 2007;1(3):e143.

[23] Fradin MS, Day JF. Comparative efficacy of insect repellents against mosquito bites. $\mathrm{N}$ Engl J Med 2002;347(1):13-18.

[24] Jelinek T. Dengue fever in international travelers. Clin Infect Dis 2000;31(1):144-7.

[25] Nelliyanil M, Joseph N, Srinivas R, et al. A study of perceptions practices and expenditure towards mosquito bite prevention among construction workers in Dakshina Kannada District. International Journal of Mosquito Research 2015;2(2):94-7.

[26] Sayavong C, Chompikul J, Wongsawass S, et al. Knowledge, attitudes and preventive behaviours related to dengue vector breeding control measures among adults in communities of Vientiane, capital of the Lao PDR. J Infect Public Health 2015;8(5):466-73. 